\title{
Investigating titanomagnetite abundance in rhyolite pumice
}

K. N. MCCARTNEY ${ }^{1 *}$, J. E. HAMMER ${ }^{1}$, T. SHEA $^{1}$, T. GIACHETTI ${ }^{2}$, S. BRACHFELD ${ }^{3}$

${ }^{1}$ University of Hawaii, Manoa., Honolulu, HI 96822, USA

(*correspondance: kmccartn@hawaii.edu)

${ }^{2}$ University of Oregon, Eugene, OR 97403, USA

${ }^{3}$ Montclair State University, Montclair, NJ 07043, USA

Examining the role of $\mathrm{nm}$ sized titanomagnetite in heterogeneous bubble nucleation is a crucial step in understanding eruptive processes. Homogeneous nucleation is the inferred form of nucleation for crystal poor systems. However, [1] shows that large decompression rates (several 10 's of $\mathrm{MPa} / \mathrm{s}$ ) and drastic changes in pressure are needed to support this hypothesis (often $>100 \mathrm{MPa}$ ). In contrast, heterogeneous nucleation occurs at $\sim 1 / 4$ the pressure change. The inference of homogeneous nucleation rests on a failure to resolve $\mathrm{nm}$ titatnomagnetite crystals petrographically, an inference that is called into question by the observance of nm-sized oxide in rhyolite tuff using magnetic characterization [2]. The aim of our study is to evaluate whether $\mathrm{nm}$ sized titanomagnetite crystals are present in nominally aphyric rhyolite tephra produced in a variety of sub-Plinian to Plinian eruptions.

Our study includes nominally aphyric materials from Medicine Lake, California, USA, (73.5 wt.\% $\mathrm{SiO}_{2}$, subplinian, $1100 \mathrm{AD})$; Diamante, Chile (74.3\% $\mathrm{SiO}_{2}$, plinian, $0.45 \mathrm{Ma})$; and Novarupta, Alaska, USA, $\left(77.2 \% \mathrm{SiO}_{2}\right.$, plinian, 1912). We determine the connected porosity and the permeability of raw and cored pumice following established methods [3]. Clasts/cores drawn from the average and $\pm 2 \sigma$ representatives of the distribution are subjected to lowtemperature magnetic remanenance experiments to detect the transition from stable single domain to superparamagnetic behavior of titanomagnetite grains $(<0.05 \mu \mathrm{m})$ as they warm from $20 \mathrm{~K}$ to $300 \mathrm{~K}$, which permits the calculation of magnetic particle volume and abundance. These techniques permit evaluation of the particle size distribution in the submicron size range [2] and thus evaluation of the possibility that magnetite crystals exist in these explosively erupted materials at number densities comparable to bubbles.

[1] Shea et al. (2017) J Volcanol and Geotherm Res, 343, pp. 155-170. [2] Worm et al. (1999) J Geophys Res, 104, pp. 25415-25425. [3] Takeuchi, Shingo (2005, 2008) J Volcanol and Geotherm Res, 58, pp. 87-100. 